
\title{
ZS Research Square \\ Higher risk for poor handwriting in Taiwanese children born late preterm
}

\author{
Yea-Shwu Hwang \\ National Cheng Kung University College of Medicine \\ Chih-Cheng Chen \\ Chang Gung Memorial Hospital Kaohsiung Branch \\ Hui-Ning Shih \\ National Cheng Kung University \\ Wen-Hui Tsai ( $\square$ whys.tsai@gmail.com ) \\ Chi Mei Medical Center https://orcid.org/0000-0002-0250-0506
}

\section{Research article}

Keywords: late preterm, early term, handwriting, grade two

Posted Date: March 15th, 2021

DOl: https://doi.org/10.21203/rs.3.rs-315563/v1

License: (9) (i) This work is licensed under a Creative Commons Attribution 4.0 International License. Read Full License 


\section{Abstract}

\section{Background}

Late preterm and early term births constitute a significant proportion of live births. However, handwriting skills of these two populations remain unclear. We aimed to investigate their risk for poor Chinese handwriting in grade two.

\section{Methods}

A total of 185 second graders born late preterm $\left(34^{+0}-36^{+6}\right.$ weeks gestation, $\left.n=54\right)$, early term $\left(37^{+0}-38^{+}\right.$ ${ }^{6}$ weeks gestation, $\left.n=56\right)$, and full term $\left(39^{+0}-41^{+6}\right.$ weeks gestation, $\left.n=75\right)$ without any intervention or diagnosis related to developmental delays were included. Their handwriting performance was rated by teachers using the Chinese Handwriting Evaluation Form (CHEF), which is a standardized handwriting scale including five handwriting dimensions (construction, accuracy, directionality, speed, and pencil grasp).

Results

After controlling for demographic risk factors, the late preterm born group had a greater risk of having worse performance in the full form (adjusted odds ratio $<\mathrm{OR}>=3.93 ; p=.038$ ) and construction dimension (adjusted OR $=4.77 ; p=.009$ ) of the CHEF than peers born at full term; whereas the risks were comparable for the early and full term born groups.

\section{Conclusions}

Late preterm but not early term born children were found to be at higher risk for poor Chinese handwriting in grade two. They particularly have difficulty with spatial construction including size, spacing, and alignment of Chinese characters and components that may influence handwriting legibility.

\section{Background}

Late preterm $\left(34^{+0}-36^{+6}\right.$ weeks' gestation) and early term births $\left(37^{+0}-38^{+6}\right.$ weeks' gestation) respectively constitute $3-6 \%$ and $15-31 \%$ of single live births across high-income countries [1]. A combined proportion of these two populations are secondary to full term births $\left(39^{+0}-41^{+6}\right.$ weeks' gestation) [2] Due to a significantly great proportion of late preterm and early term births, it appears important to understand the effects of these near-term births on developmental outcomes.

In recent decades, more and more studies have shown that being born a few weeks early indeed increases the risk for adverse developmental outcomes [3]. A few population-based studies have consistently indicated that late preterm and early term born infants and preschoolers are at a slightly but significantly increased risk of having neurodevelopmental delays [4,5]. For instance, studies have reported that compared to the reference group born at full term, the range of odds ratio (OR) for 
developmental delay risk was shown to be 1.37-2.58 for late preterm and 1.22-1.56 for early term born children, respectively $[4,5]$. Therefore, more children born late preterm $(23.5 \%)$ and early term $(14.9 \%)$ require early intervention programs as compared to their full term born peers (11.9\%) [6]. Those children born late preterm and early term births were found to continue to perform poorer than those born full term, including increased needs for special educational support and scored lower in various academic subjects (reading, math, literacy, and writing) compared to their peers born full term [7-10]. However, school functioning in these children has not been fully investigated. For example, little is known about the handwriting function of children born late preterm and early term in the literature.

Proficient handwriting is an essential academic skill. Elementary school children particularly in first grades spend a lot of time learning handwriting [11]. However, some children encounter handwriting difficulties, including illegible handwriting and slow writing speed. Illegible handwriting is often the result of inappropriate spatial construction of letters and words (e.g., spacing of letters within words, size of the letter relative to the writing guideline) or/and errors in letter formation (e.g., improper letter forms, incomplete letter closures, upside-down letters) $[12,13]$. These components of legibility can be separately investigated in examining child's handwriting legibility problems. In terms of the results of factor analysis, four legibility-related factors (letter formation, spacing, alignment, size) in the alphabetic system [14] and three legibility-related factors (construction, accuracy, directionality) in the Chinese system have been identified $[12,15]$. The problems in the construction factor consist of inappropriate size, spacing, and alignment of Chinese characters and components. The malformations of characters (e.g., adding or missing strokes) are belonged to the accuracy problems. The directionality problems consist of upside down or reversed components shown in Chinese characters $[12,15,16]$.

There were limited number of studies in the literature investigating handwriting performance of children born prematurely [17-19]. Also, most of studies focused on very and moderate preterm born children defined as those born at less than 34 weeks of gestation $[17,18]$. In one study working on very and moderate preterm children, researchers have found that those children had significantly lower scores in letter and word legibility and writing speed compared with term born classmates in the assessment of the Evaluation Tool of Children's Handwriting-Manuscript [17]. Also, in terms of teacher's rating, studies consistently found that a higher proportion of very and moderate preterm-born children were rated as performing at below average or very poor levels in handwriting than their peers born at term $[17,18]$. Their results have revealed the adverse impact of early preterm birth on handwriting performance. Whether this impact of early birth extents to children born at beyond 34 weeks of gestation is uncertain.

In this study, we aimed to compare the risk of having handwriting difficulties in children born late preterm, early term, and full term using a standardized, multi-dimensional Chinese handwriting questionnaire. Furthermore, whether there were difficulties in specific handwriting dimensions for children born late preterm and early term was also addressed.

\section{Method}




\section{Participants}

This study was a part of a large project related to the handwriting performance of second graders born at different gestational weeks. The project was conducted from November 2015 to May 2017. The children's handwriting performance was evaluated in the second semester of their second grade using the Chinese Handwriting Evaluation Form (CHEF) [16].

In this project, there were two methods to recruit preterm children born below 37 weeks of gestation. One was to invite the parents of preterm children who were registered in the preterm baby registration records of a medical center in Tainan to participate in the study by telephone. The other method was to recruit preterm children through a research leaflet given to the parents of second graders attending elementary schools in Tainan. Children born at or more than 37 weeks of gestation were recruited from the second grades of elementary schools in Tainan, Taiwan. If the class teachers agreed to participate, they were asked to give our research package including study proposal, written informed consent, and demographic questionnaire to the parents of five randomly selected children in their class on our behalf. The detailed procedure for the data collection in this project was described in a study by Shih et al. (2018).

For the purpose of this study, children born at $34^{+0}-41^{+6}$ weeks of gestational age (GA) with native Chinese speaking parents were analyzed. The exclusion criteria included (1) congenital anomalies, (2) genetic or chromosome abnormalities, (3) auditory and visual problems that cannot be corrected to a normal range, (4) a diagnosis of neurodevelopmental disorders (e.g., cerebral palsy, attention deficit hyperactivity disorder, autism spectrum disorder, and intellectual disabilities), (5) a history of early intervention related to developmental delays, or (6) injuries in the neuromuscular system of the trunk or upper extremities that may affect handwriting performance. Then, according to the child's gestational weeks at birth, the participants were classified into late preterm, early term, and full term born groups.

\section{Measures}

\section{Chinese Handwriting Evaluation Form (CHEF)}

The CHEF is a standardized, norm-referenced, teacher-reported handwriting questionnaire developed by Taiwanese researchers to detect handwriting difficulties in first and second graders [16]. A total of 25 item questions describing problematic performance in five dimensions (construction, accuracy, speed, pencil grasp, and directionality) were rated by the child's class teacher using a 5-point Likert scale (1: never matching to 5: always matching). Eight items in the construction dimension are related to problems in size, spacing, and alignment of Chinese characters and components. Five items in the accuracy dimension relate to the malformation of characters (i.e., incorrect configuration of components, adding or missing strokes), incorrect stroke sequence, and poor literacy grades. Two items in the directionality dimension were used to identify problems where the character components are upside down or reversed. The performance in the above three dimensions influences handwriting legibility. Four items in the speed dimension consist of slow writing speed, inattention to handwriting tasks, messiness shown on the homework or test sheets, and failure to finish handwriting tasks on time. The pencil grasp dimension 
includes six items describing problematic biomechanical characteristics of pencil grasp (e.g., pencil tip pressure on paper, tight grip). A higher score means poorer handwriting performance. A cut-off percentile of $15 \%$ indicates " handwriting difficulty," as suggested by the test manual [16].

The psychometric properties of the CHEF have been examined and provided in the test manual [16]. Its internal consistency (Cronbach $a=.70-.93)$, test-retest reliability $(r=.79-.90)$, and split-half reliability ( $r$ $=.64-.98)$ are acceptable to good. The discriminative validity of the CHEF has been proven in children with typical handwriting and in those having difficulty with handwriting. The concurrent validity of the $\mathrm{CHEF}$ and the handwriting Battery of Chinese Basic Literacy subscales has been validated. The inter-rater reliability has not been established by the developers [16]. There is only one class teacher for each class in Taiwanese elementary schools, who teach all literacy and mathematic courses [16]. Thus in this study, we established the inter-rater reliability of the CHEF by asking 14 mothers who well knew their child's handwriting performance (i.e., the mothers rating 7-10 points in the scale of familiarity with the child's handwriting performance using a 10-point Likert scale) to fill out the CHEF simultaneously. Significantly strong correlations between the teachers' and mothers' ratings in all dimensions $(r=.75-.89, p \leq .01)$ and full form $(r=.90, p<.001)$ of the CHEF indicated that the CHEF has good-excellent inter-rater reliability expect of the pencil grasp dimension $(r=.53, p=.093)$.

\section{Sociodemographic Questionnaire}

This self-designed questionnaire consists of questions about the child's birth and medical history, handedness, and maternal age and education. Mothers were asked to fill out this questionnaire.

\section{Procedure}

Parents who agreed to participate in this study were asked to fill out the demographic questionnaire. Then their child's class teachers were invited to participate in this study. Teachers were asked to observe the target child's handwriting performance and then completed the CHEF and returned it to the first author by mail. To avoid bias, teachers were blind to student's birth history.

\section{Data Analysis}

Depending on the type of data (continuous or categorical), one-way analysis of variance (ANOVA) or chisquared method was used to compare the demographic characteristics of the three gestational age groups (late preterm, early term, and full term). The odds ratio (OR) and $95 \%$ confidence interval (Cl) of poor handwriting for the late preterm and early term born groups were estimated using multivartiate logistic analyses with full term birth group as the reference group after controlling for potentially confounding factors including the child's age and sex and maternal educational levels. All analyses were conducted using SPSS 17.0 software (SPSS Inc. Chicago, IL, USA). The statistical significance was set as $p<.05$ in all analyses.

\section{Results}




\section{Child's characteristics}

The data of 185 children (late preterm: 54 , early term: 56 , and full term: 75 ) meeting the criteria were included in the analysis. They studied in 90 grade-two classes of 47 elementary schools in Tainan at the time of study. Their demographic characteristics are described in Table 1. There was a significant difference in gestational age $(p<.001)$, birthweight $(p<.001)$, and maternal educational levels $(p=.016)$ among the three groups. A greater percentage of mothers in the late preterm group (73.7\%) had higher educational levels (i.e., completing college/university or higher degrees) as compared to the early term $(47.3 \%)$ and full term (57.3\%) groups. No group differences were found in the children's chronological age, sex, handedness, and maternal age (Table 1).

Table 1

Characteristics of the three gestational age groups

\begin{tabular}{|c|c|c|c|c|}
\hline & $\begin{array}{l}\text { Late preterm } \\
(n=54)\end{array}$ & $\begin{array}{l}\text { Early term } \\
(n=56)\end{array}$ & $\begin{array}{l}\text { Full term } \\
(n=75)\end{array}$ & $p$ \\
\hline \multicolumn{5}{|l|}{ Child } \\
\hline Age (months) & $97.1(3.5)$ & $97.6(4.2)$ & $98.1(4.2)$ & .395 \\
\hline boy, $n(\%)$ & $31(57.4)$ & $21(37.5)$ & $32(42.7)$ & .092 \\
\hline GA (weeks) & $35.7(0.8)$ & $38.1(0.5)$ & $39.7(0.7)$ & $<.001$ \\
\hline Birthweight (g) & $2522(568)$ & 3144 (425) & $3182(362)$ & $<.001$ \\
\hline Right handedness, $n(\%)$ & $49(90.7)$ & 53 (94.6) & $68(90.7)$ & .092 \\
\hline \multicolumn{5}{|l|}{ Mother } \\
\hline Age & $39.4(3.8)$ & $38.2(4.3)$ & $38.0(4.3)$ & .141 \\
\hline $\begin{array}{l}\text { Education } \\
\text { (< college), } n(\%)\end{array}$ & $14(25.9)$ & $30(52.7)$ & $32(42.7)$ & .016 \\
\hline
\end{tabular}

\section{Poor Chinese Handwriting in the Gestational Age Groups}

Table 2 shows the proportion of children with poor handwriting in the three gestational age groups. The relative risk of poor handwriting for both groups born late preterm and early term compared with the reference group born full term is presented in Table 3. The proportion of late preterm born children with poor performance in various handwriting dimensions seemed higher than peers born at full term, particularly in the full form ( $18.5 \%$ vs. $5.3 \%$ ) and the construction dimension (25.9\% vs. $6.7 \%)$ (Table 2 ). After controlling for the child's age, sex, and maternal education, the results of the multivariate logistic analyses indicated that children born late preterm had a higher risk of having poor handwriting in the full 
form (adjusted $\mathrm{OR}=3.93 ; 95 \% \mathrm{Cl}=1.08-14.32 ; p=.038$ ) and the construction dimension (adjusted $\mathrm{OR}=$ $4.77 ; 95 \% \mathrm{Cl}=1.48-15.37 ; p=.009)$ as compared to those born at full term.

Table 2

The proportion of children with poor Chinese handwriting

\begin{tabular}{|llll|}
\hline \multicolumn{3}{|c|}{$n(\%)$} & \\
\hline & $\begin{array}{l}\text { Late preterm } \\
(n=54)\end{array}$ & $\begin{array}{l}\text { Early term } \\
(n=56)\end{array}$ & $\begin{array}{l}\text { Full term } \\
(n=75)\end{array}$ \\
\hline CHEF-full form & $10(18.5)$ & $3(5.4)$ & $4(5.3)$ \\
\hline CHEF-dimension & & \\
\hline Construction & $14(25.9)$ & $2(3.6)$ & $5(6.7)$ \\
\hline Accuracy & $8(14.8)$ & $2(3.6)$ & $6(8.0)$ \\
\hline Speed & $9(16.7)$ & $2(3.6)$ & $8(10.7)$ \\
\hline Pencil grasp & $6(11.1)$ & $6(10.7)$ & $4(5.3)$ \\
\hline Directionality & $7(13.0)$ & $3(5.4)$ & $8(10.7)$ \\
\hline CHEF = Chinese Handwriting Evaluation Form & \\
\hline
\end{tabular}

Table 3

Risk for poor handwriting in second graders $(n=185)$ using multivariate logistic analyses

\begin{tabular}{|c|c|c|c|c|c|c|}
\hline & \multicolumn{2}{|c|}{ Full form } & \multicolumn{2}{|c|}{ Construction } & \multicolumn{2}{|c|}{ Accuracy } \\
\hline & OR & $(95 \% \mathrm{Cl})$ & OR & $(95 \% \mathrm{Cl})$ & OR & $(95 \% \mathrm{Cl})$ \\
\hline \multicolumn{7}{|c|}{ Gestational age } \\
\hline Late preterm & $3.93^{*}$ & $\begin{array}{l}(1.08- \\
14.32)\end{array}$ & $4.77^{\star \star}$ & $\begin{array}{l}(1.48- \\
15.37)\end{array}$ & 2.21 & $\begin{array}{l}(0.64- \\
7.64)\end{array}$ \\
\hline Early term & 0.49 & $(0.08-3.18)$ & 0.47 & $(0.08-2.73)$ & 0.25 & $\begin{array}{l}(0.04- \\
1.55)\end{array}$ \\
\hline Sex (boy) & $5.56^{\star \star}$ & $\begin{array}{l}(1.53- \\
20.19)\end{array}$ & $7.03^{* *}$ & $\begin{array}{l}(2.05- \\
24.05)\end{array}$ & $4.78 *$ & $\begin{array}{l}(1.35- \\
16.97)\end{array}$ \\
\hline Age (month) & $0.81 *$ & $(0.69-0.96)$ & 0.90 & $(0.78-1.02)$ & $0.81 *$ & $\begin{array}{l}(0.68- \\
0.96)\end{array}$ \\
\hline $\begin{array}{l}\text { Maternal } \\
\text { education } \\
\text { (<college) }\end{array}$ & 2.76 & $(0.84-9.12)$ & 2.11 & $(0.71-6.23)$ & $6.94 * \star$ & $\begin{array}{l}(1.94- \\
24.76)\end{array}$ \\
\hline
\end{tabular}


Table 3

(continued)

\begin{tabular}{|c|c|c|c|c|c|c|}
\hline & \multicolumn{2}{|c|}{ Speed } & \multicolumn{2}{|c|}{ Pencil grasp } & \multicolumn{2}{|c|}{ Directionality } \\
\hline & OR & $(95 \% \mathrm{Cl})$ & OR & $(95 \% \mathrm{Cl})$ & OR & $(95 \% \mathrm{Cl})$ \\
\hline \multicolumn{7}{|l|}{ Gestational age } \\
\hline Late preterm & 1.43 & $\begin{array}{l}(0.49- \\
4.16)\end{array}$ & 1.88 & $\begin{array}{l}(0.49- \\
7.21)\end{array}$ & 1.19 & $\begin{array}{l}(0.38- \\
3.71)\end{array}$ \\
\hline Early term & 0.14 & $\begin{array}{l}(0.02- \\
1.20)\end{array}$ & 1.90 & $\begin{array}{l}(0.48- \\
7.54)\end{array}$ & 0.35 & $\begin{array}{l}(0.08- \\
1.54)\end{array}$ \\
\hline Sex (boy) & 2.91 & $\begin{array}{l}(0.97- \\
8.74)\end{array}$ & 1.93 & $\begin{array}{l}(0.64- \\
5.59)\end{array}$ & 2.26 & $\begin{array}{l}(0.77- \\
6.62)\end{array}$ \\
\hline Age (month) & 0.88 & $\begin{array}{l}(0.77- \\
1.01)\end{array}$ & 0.96 & $\begin{array}{l}(0.84- \\
1.11)\end{array}$ & $0.80 * \star$ & $\begin{array}{l}(0.69- \\
0.93)\end{array}$ \\
\hline $\begin{array}{l}\text { Maternal education }(< \\
\text { college) }\end{array}$ & 1.32 & $\begin{array}{l}(0.46- \\
3.86)\end{array}$ & 0.74 & $\begin{array}{l}(0.23- \\
2.36)\end{array}$ & 2.26 & $\begin{array}{l}(0.87- \\
7.51)\end{array}$ \\
\hline
\end{tabular}

There was a similar proportion of children with poor handwriting in each dimension and the full form in the groups born early term and full term (Table 2). The adjusted risk of having poor handwriting for early and full term born children was not significant (Table 3).

\section{Demographic Characteristics and Poor Handwriting Performance}

The results of the multivariate logistic regression indicated that the child's age, sex, and maternal educational levels independently contributed to the performance in specific handwriting dimensions (Table 3). Every additional month of age was significantly associated with a small degree of decreased risk of poor performance in the dimensions of accuracy and directionality, and the full form of the CHEF. In addition, boys were at significantly greater risk for poor performance in the dimensions of construction and accuracy and the full form than girls. A sex-difference in the risk of poor performance in the speed dimension approached a statistical difference. Also, children of mothers who had completed college/university education or higher were at lower risk of poor performance in the accuracy dimension (Table 3). No demographic variable was significantly correlated with poor performance in the pencil grasp dimension.

\section{Discussion}

Our results showed that after controlling for the child's age, sex, and maternal educational levels, the risk of poor handwriting for late preterm born children was approximately fourfold as high as their full-term 
peers in the second grade. To our knowledge, this was the first study to investigate the handwriting performance of children born late preterm. The present findings on handwriting performance of late preterm born children were consistent with the previous findings, which indicated that this population were still at a higher risk for poor developmental outcomes than children born at term even though their gestational weeks were near term $[4,5]$. However, our findings were slightly different from Feder et al.'s findings on handwriting performance of children born below 34 weeks of gestation, who demonstrated both problems of poor legibility and slow speed [17]. Our late preterm participants had handwriting difficulty particularly in the dimension of Chinese character construction, one component of legibility. This inconsistency may be attributed to the difference of gestational weeks at birth. As expected, earlier preterm births generally lead to greater adverse impacts on brain development [20] and developmental outcomes [9].

Our results demonstrated that even in the absence of history related to developmental delays after birth, close to $20 \%$ of late preterm children performed the worst in handwriting. This finding implies some mild deficits in late preterm children may be not discovered until they are required to complete complicated tasks (e.g., handwriting) when they are older. Future studies are required to further investigate the relationship between early medical factors and poor handwriting to define the high-risk subgroup born late preterm. A long-term, comprehensive developmental follow-up program may be provided to them to prevent later difficulties in school function.

As mentioned before, the late preterm children particularly had difficulty with spatial construction of Chinese characters and components, including spacing, size, alignment, and slant, which may lead to handwriting illegibility. Previous studies have demonstrated that visual perception [17], tactile and kinesthetic perceptions [21], visuomotor integration [22, 23], in-hand manipulation (i.e., translation and rotation of a small peg within one hand), and motor coordination (i.e., tracing the forms by connecting dots within provided paths) [23] are significant factors related to handwriting legibility. Future research can examine the relationships among these potentially underlying factors and the poor character construction in late preterm children to provide a guide for supportive intervention for their handwriting problems.

Regarding developmental outcomes of children born early term, previous studies have indicated that they have a slightly increased risk of developmental (e.g., language and cognitive problems) and school functional problems (e.g., lower academic achievement) than their peers born at full term $[5,7,8]$. However, we did not find such a difference between early term and full term children in terms of their handwriting performance. The absence of a significant difference between these two gestational age groups in our study may partially be a result of a higher ratio of 38 weeks to 37 weeks gestation in our early term group (4.6:1). The ratio of 38 weeks to 37 weeks gestation shown in the population cohorts is approximately $3: 1$ in the literature $[9,24]$. Recent studies have reported that compared to children born at full term, a significantly poorer cognitive development [25] and school achievement (grammar and numeracy) [9] is mainly found in those born at 37 weeks but not at 38 weeks of gestation. Whether there 
is a similar difference in handwriting between children born 37 and 38 weeks of gestation requires further investigation with larger sample.

Our results demonstrated an independent contribution of some demographic factors to poor handwriting in grade two, including being younger, being male, and having mothers with below collage/university education. The later-born effect on school performance was consistently found in other studies, which revealed the associations between older age at the entrance of elementary school and lower risk of poor handwriting [26] and higher academic achievements in the first grade [27]. In addition, consistent with Feder et al.'s findings on English legibility [17], we also found that boys had a greater risk of having difficulties in Chinese handwriting legibility as compared to girls. Furthermore, there was a significant association between maternal education levels and the risk of poor performance in the accuracy dimension. These results suggest that these demographic risk factors are important to be considered in investigating the handwriting performance of students in the lower elementary school grades.

There were a few limitations in the present study, such as a small convenience sample and subjective ratings of class teachers on the children's handwriting performance. A larger sample size and direct handwriting assessment tools would be needed to confirm our findings. In addition, future studies examining the handwriting performance of late preterm children using different languages are also necessary.

\section{Conclusions}

This preliminary investigation indicated that children born late preterm may be at a greater risk of poor Chinese handwriting than their full term born peers based on teacher reports using a validated handwriting questionnaire. The main handwriting problem for these children is to construct appropriate spatial relationship among components and characters. On the other hand, early term and full term born children have comparable risks of have poor performance in all handwriting dimensions. The underlying components affecting poorer character and components construction in children born late prematurely and the proper intervention for this handwriting problem need further investigation.

\section{Abbreviations}

CHEF: the Chinese Handwriting Evaluation Form; OR: odds ratio; Cl: confidence interval; GA: gestational age.

\section{Declarations}

\section{Acknowledgements}

We would like to thank the parents and teachers who participated in this study. Thanks to Ms. Yu-Ting Hu for her assistance in data analysis. 


\section{Authors' contributions}

Dr. YSH designed the study, supervised data collection, interpreted the data, and draft the manuscript. Dr. CCC coordinated and supervised data collection. Miss HNS performed data collection and statistical analysis. Dr. WHT contributed to the study design and data interpretation, and made critical revision of the manuscript. All authors read and approved the final manuscript.

\section{Funding}

Funding for this study was supported by the Ministry of Science and Technology, Taiwan (MOST 1042410-H-006-068), Chi Mei Medical Center (CMFHR 10604), and the Summer Research Project Grant of Medicine College at National Cheng Kung University (NCKUMCS 2018008).

\section{Availability of data and materials}

The dataset used and analyzed during the current study were available from the corresponding author on reasonable request.

\section{Ethics Approval and consent to participate}

All procedures performed in studies involving human participants were in accordance with the 1964 Helsinki declaration. This project was approved by the Institutional Review Board of Chi Mei Medical Center (No. 10310-006). Written informed consent was obtained from all parents and class teachers before data collection was initiated.

\section{Consent for publication}

Not applicable.

\section{Conflict of Interest}

The authors declare that they have no conflict of interest.

\section{Author details}

${ }^{1}$ Department of Occupational Therapy, College of Medicine, National Cheng Kung University, Tainan, Taiwan

${ }^{2}$ Section of Neonatology, Department of Pediatrics, Chang Gung Memorial Hospital Kaohsiung Branch and Chang Gung University, College of Medicine, Kaohsiung, Taiwan

${ }^{3}$ Division of Neonatology, Department of Pediatrics, Chi Mei Medical Center, Tainan, Taiwan

${ }^{4}$ Graduate Institute of Medical Sciences, College of Health Sciences, Chang Jung Christian University, Tainan, Taiwan 


\section{References}

1. Delnord M, Zeitlin J. Epidemiology of late preterm and early term births-An international perspective. Semin Fetal Neonat M. 2019; 24: 3-10.

2. Stewart DL, Barfield WD. Updates on an at-risk population: late-preterm and early-term infants. Pediatrics. 2019;144(5):e20192760.

3. Chan E, Leong P, Malouf R, Quigley MA. Long-term cognitive and school outcomes of late-preterm and early-term births: a systematic review. Child: Care HIth Dev. 2016;42(3):297-312.

4. Schonhaut L, Armijo I, Perez M. Gestational age and developmental risk in moderately and late preterm and early term infants. Pediatrics. 2015;135(4):e835-41.

5. Stene-Larsen K, Brandlistuen RE, Lang AM, Landolt MA, Latal B, Vollrath ME. Communication impairments in early term and late preterm children: a prospective cohort study following children to age 36 months. J Pediatr. 2014;165(6):1123-8.

6. Shapiro-Mendoza C, Kotelchuck M, Barfield W, Davin CA, Diop H, Silver M, et al. Enrollment in early intervention programs among infants born late preterm, early term, and term. Pediatrics. 2013;132(1):e61-9.

7. Chan E, Quigley MA. School performance at age 7 years in late preterm and early term birth: a cohort study. Arch Dis Child Fetal Neonatal Ed. 2014;99(6):F451-7.

8. Nielsen TM, Pedersen MV, Milidou I, Glavind J, Henriksen TB. Long-term cognition and behavior in children born at early term gestation: a systematic review. Acta Obstet Gynecol Scand. 2019;98(10):1227-34.

9. Searle AK, Smithers LG, Chittleborough CR, Gregory TA, Lynch JW. Gestational age and school achievement: a population study. Arch Dis Child Fetal Neonatal Ed. 2017;102(5):F409-f16.

10. Woythaler M. Neurodevelopmental outcomes of the late preterm infant. Semin Fetal Neonatal Med. 2019;24(1):54-9.

11. McHale K, Cermak SA. Fine motor activities in elementary school: Preliminary findings and provisional implications for children with fine motor problems. Am J Occup Ther. 1992;46(10):898903.

12. Chang SH, Yu NY. Evaluation and classification of types of Chinese handwriting deficits in elementary schoolchildren. Percept Mot Skills. 2005;101(2):631-47.

13. Schneck CM, Case-Smith J. Prewriting and handwriting skills. In: Case-Smith J, O'Brien J, editors. Occupational therapy for children and adolescents. St. Louis: Mosby; 2015. p. 498-519

14. Ziviani J, Elkins J. An evaluation of handwriting performance. Educ Rev. 1984;36(3):249-61.

15. Tseng MH. Factorial validity of the Tseng handwriting problem checklist. Journal of the Occupational Therapy Association of the Republic of China. 1993;11:13-26.

16. Chang SH, Yu NY. Chinese Handwriting Evaluation Form (CHEF). Taipei, Taiwan: Psychological Publishing. 2012. 
17. Feder KP, Majnemer A, Bourbonnais D, Platt R, Blayney M, Synnes A. Handwriting performance in preterm children compared with term peers at age 6 to 7 years. Dev Med Child Neurol. 2005;47(3):163-70.

18. Pritchard VE, Clark CA, Liberty K, Champion PR, Wilson K, Woodward LJ. Early school-based learning difficulties in children born very preterm. Early Hum Dev. 2009;85(4):215-24.

19. Shih HN, Tsai WH, Chang SH, Lin CY, Hong RB, Hwang YS. Chinese handwriting performance in preterm children in grade 2. PloS one. 2018;13(6).

20. van Soelen ILC, Brouwer RM, Peper JS, van Beijsterveldt T, van Leeuwen M, de Vries LS, et al. Effects of gestational age and birth weight on brain volumes in healthy 9 year-old children. J Pediatr. 2010;156(6):896-901.

21. Yu TY, Hinojosa J, Howe TH, Voelbel GT. Contribution of tactile and kinesthetic perceptions to handwriting in Taiwanese children in first and second grade. OTJR-Occup Part Hea. 2012;32(3):8794.

22. Cornhill H, Case-Smith J. Factors that relate to good and poor handwriting. Am J Occup Ther. 1996;50(9):732-9.

23. Lee $\mathrm{TI}$, Howe $\mathrm{TH}$, Chen HL, Wang TN. Predicting handwriting legibility in Taiwanese elementary school children. Am J Occup Ther. 2016;70(6):7006220020p1-p9.

24. Smithers L, Searle A, Chittleborough C, Scheil W, Brinkman S, Lynch J. A whole-of-population study of term and post-term gestational age at birth and children's development. BJOG-Int J Obstet Gy. 2015;122(10):1303-11.

25. Hua J, Sun J, Cao Z, Dai X, Lin S, Guo J, et al. Differentiating the cognitive development of early-term births in infants and toddlers: A cross-sectional study in China. BMJ open. 2019;9(4):e025275.

26. Hwang YS, Su PF, Hsiao YL, Tsai WH, Hung JY. Developing a nomogram model to predict the risk of poor Chinese handwriting in first grade. Am J Occup Ther. 2020; 74(5):7405205080p17405205080p8. doi: 10.5014/ajot.2020.038711.

27. Puhani PA, Weber AM. Does the early bird catch the worm? Instrumental variable estimates of early educational effects of age of school entry in Germany. Empir Econ. 2007;32:359-86. 